With its excellent illustrations--18 plates, six in colour, by Chloe Talbot Kelly -and its wealth of information this book will be indispensable for ornithologists visiting New Zealand, and fascinating even to those who may never have the opportunity.

E. M. NICHOLSON

\title{
Zoos of the World, by James Fisher. Aldus Books, 45s.
}

The steady improvement of the zoological garden is one of the most interesting recent developments in the field of wildlife conservation, education and research. Traditionally zoos have been regarded as places of amusement and entertainment, but in the past decade the climate of opinion has changed considerably. Zoos are becoming increasingly aware of their educational responsibilities and their vital role in wildlife conservation by designing attractive, educational exhibits which will stimulate an interest in wild animals, collecting information on the wild animals in their care, and breeding rare animals.

Mr. Fisher shows how this change has come about. Based on his extensive knowledge of the history of zoos, experience of the numerous zoos he has visited, and statistics from the International Zoo Yearbook, he traces the development of the zoological garden from the menageries of the Ancient Egyptians in the third millennium BC, to the zoos of Rome and the Middle Ages, up to the present day. He examines the various aspects of the modern zoo, describing what is involved in the day-to-day running of a zoo, the breeding of animals in captivity, conservation activities, ways in which zoos obtain their animals, the trends in modern zoo design and construction, and the types of research being undertaken in the larger zoos today. His final chapter describes the tremendous progress zoos are making in improving their exhibits. The book is lavishly illustrated with blackand-white or colour photographs on every page.

As a guide to the ordinary member of the public, who would like to know what to look for when visiting a zoo, and to the conservationist or scientist who wants to know more about the educational or scientific role of the modern zoo, the book is invaluable. As Mr. Fisher says in his last chapter, he has tried to show that "zoos are part of man's deepest strivings to understand the world around him; that without them he would have learned much less than the little he knows about the animals he shares the world with; that with them he has found vast scope for research, scholarship, architectural imagination, conservation, preservation, tenderness, self-expression, and a lot of innocent fun."

CAROLINE MEDWAY

\section{Studying our Fellow Mammals, by Ernest P. Walker. Animal Welfare Institute, New York, $\$ 1.00$.}

The author has had long experience in the handling and care of mammals. As first commissioner of the Alaska Game Commission, head of the Federal Game and Bird Reservations, and finally assistant director of the Smithsonian Institution's National Zoological Park, he has acquired a wide knowledge of animal needs and methods of observing their behaviour. Not all zoologists would agree with some of the views expressed in this short, simply written book, but the 'Walker philosophy' is humane, informative and certainly stimulating. He has jotted down his thoughts, and they cover a vast field - conservation, behaviour, anatomy and physiology, care of captive animals, photography, classification and distribution-and he raises many thought-provoking subjects which should be of special interest to teachers for class discussion.

W. N. SCOTT 